\title{
Structural, biochemical, and physiological characterization of photosynthesis in leaf-derived cup-shaped galls on Litsea acuminata
}

\author{
Meng-Yuan Huang ${ }^{1 \dagger}$, Wen-Dar Huang ${ }^{2 \dagger}$, Hsueh-Mei Chou ${ }^{3}$, Chang-Chang Chen ${ }^{4}$, Pei-Ju Chen ${ }^{5}$, \\ Yung-Ta Chang ${ }^{5^{*}}$ and Chi-Ming Yang ${ }^{6^{*}}$
}

\begin{abstract}
Background: The source and sink relationships between insect-induced galls and host plant leaves are interesting. In this research, we collected cup-like galls induced by Bruggmanniella sp. (Diptera: Cecidomyiidae) on host leaves of Litsea acuminata and assessed them to investigate source-sink relationships between galls and host leaves. We characterized several of their photosynthetic characteristics including chlorophyll fluorescence (Fv/Fm), stomatal conductance, and photosynthetic capacity, biochemical components such as total soluble sugar, starches, free amino acids, and soluble proteins. The structural analyses were performed under confocal, light, and scanning electron microscopies.
\end{abstract}

Results: Compared with host leaves, galls exhibited slightly lower chlorophyll fluorescence; however, stomatal conductance and photosynthetic capacity were not detected at all. Galls accumulated higher total soluble sugars and free amino acids but less soluble proteins than host leaves. No stomata was observed on exterior or interior gall surfaces under light or scanning electron microscopy, but their inner surfaces were covered with fungal hyphae. Confocal imagery showed a gradient of chloroplasts distribution between gall outer and inner surfaces.

Conclusions: Our results strongly suggest that leaf-derived cecidomyiid galls are a type of chlorophyll-deficient non-leaf green tissue and consists on a novel sink in L. acuminate.

Keywords: Cecidomyiidae, Gall, Litsea acuminate, Photosynthesis, Chlorophyll fluorescence, Sink

\section{Background}

Insect larvae residing inside galls use these leaf-derived structures as shelters for protection and sources of nutrition. More than $65 \%$ of galls, with various appearances and colors, are derived from the leaves of their host plants within which the larvae reside. Three major hypotheses involving nutrition, environment, and enemies have been postulated to explain the adaptive significance of gall induction and understand the evolution of gall morphology [1]. However, the source-sink relationships between insect-induced galls and host leaves are still disputed. Gall-inducing insects have developed highly

\footnotetext{
* Correspondence: biofv031@ntnu.edu.tw; cmyang@gate.sinica.edu.tw ${ }^{\dagger}$ Equal contributors

${ }^{5}$ Department of Life Science, National Taiwan Normal University, Taipei 116Wenshan, Taiwan

${ }^{6}$ Biodiversity Research Center, Academia Sinica, Taipei 115Nankang, Taiwan Full list of author information is available at the end of the article
}

specialized and nutritional relationships with their host plants because these insects spend major portions of their lives within galls. They interact with galls by the simple removal of tissue or by damaging vascular tissues in order to manipulate the synthesis and transport of host plant nutrients [2-5]. Also, plants can use the galls as sinks for nutrients for insects' growth and reproduction $[6,7]$.

We have previously pointed out that prior studies on gall-caused impacts to host leaf photosynthesis do not suggest any general trends; however, Yang et al. $[8,9]$ reported a range of effects from negative to positive. This lack of pattern has not been confirmed within the past decade, therefore this question still remains under dispute and requires further exploration.

Regardless of whether net photosynthesis is directly measured in galls or estimated from radioactive labeling 
experiments, the photosynthetic rates in galls are usually much lower than in unattacked normal leaf tissues [10]. Aldea et al. [11] found lower photosystem (PS) II efficiency, as determined by chlorophyll fluorescence (Fv/Fm), in Cecidomyia galls on Carya glabra leaves, Cynipid galls on Quercus velutina leaves, and eriophyid galls on Ulmus alata leaves compared to uninfected leaf surfaces. Photosynthetic rates of galled leaves, measured by gas exchange, were reduced when compared to ungalled leaves of naturally growing Prunus serotina and Rhus glabra [12]. Water potential, photosynthesis rate (indicated by gas exchange), transpiration, and stomatal conductance were decreased on leaves of Parthenium hysterophorus with Epiblema strenuana galls [13]. The Asian chestnut gall wasp was reported to reduce the photosynthesizing leaf area by around $40 \%$ when compared to a non-galled leaf. It also induces reduction in photosynthetic capacity $(\sim 60 \%)$ and stomatal conductance $(\sim 50 \%)$ [14]. It has also been noted that gall-inducing mites, such as Vasates aceriscrumena, may be the major drivers of age-dependent reductions in the physiological performance and growth of the canopy leaves of mature sugar maples (Acer saccharum) [15].

In contrast, the phyllodes of Acacia pycnantha with wasp-induced galls had higher photosynthetic rates as indicated by gas exchange than similarly aged control phyllodes without galls [10]. Photosynthesis (indicated by gas exchange), stomatal conductance, and water potential were increased on Silphium integrifolium leaves with Antistrophus silphii galls compared to ungalled shoots [16]. A scale insect on leaves of Ilex aquifolium also caused a higher PSII energy transduction efficiency, as indicated by chlorophyll fluorescence $(\mathrm{Fv} / \mathrm{Fm})$, in affected tissues relative to uninfected tissues [17].

The characterization of gall transcriptomes in grape leaves shows that galling insects increase their primary metabolic gene expression, including glycolysis, fermentation, and the transport of water, nutrients, and minerals in leaf-derived gall tissues, and decrease the expression of genes responsible for non-mevalonate and terpenoid synthesis, but increase the biosynthesis of shikimate and phenylpropanoid, which are secondary metabolites that alter the defense status of grapes [18]. Investigation of the metabolic responses of pteromalid wasp (Trichilogaster acaciaelongifoliae) larvae in bud galls on Acacia longifolia to reduced oxygen $\left(\mathrm{O}_{2}\right)$ and elevated carbon dioxide $\left(\mathrm{CO}_{2}\right)$ indicates that the larvae are tolerant to hypoxia/hypercarbia and are capable of reducing their respiratory rates to cope with hypercarbia [19]. Symbiosis between gall-inducing insects and fungi catalyze their expansion of resource use (niche expansion) and diversification (i.e., the evolution of symbiotic interactions leads to niche expansion), which in turn catalyzes additional diversification [20].
In previous studies, we concluded that two leafderived cecidomyiid galls, the red ovoid galls induced by $D$. taiwanensis and the green obovate galls induced by Daphnephila sueyenae, are photoassimilative sinks in Machilus thunbergii (Lauraceae) leaves. This data also implies that insect-induced galls may have chlorophylldeficient non-leaf green tissues composed to a very high extent of heterotrophic tissues and autotrophic tissues to a much lower extent $[8,9,21]$.

The 'Ambrosia' gall midges, significant portion of the family Cecidomyiidae, are one of the most diverse and widespread groups of insects known to engage in symbiotic associations with fungi. The galls induced by these midges are typically lined internally with fungal hyphae, which the developing larva may feed upon [22]. The cup-shaped gall induced by Bruggmanniella sp. also contained an associated fungus. Litsea acuminata is an abundant and common subtropical tree species that is widely distributed in Taiwan. It is located $400 \sim 2,000 \mathrm{~m}$ above sea level (asl) in Taiwan, and can grow to $20 \mathrm{~m}$ in height with profuse branching. A cup-shaped gall induced by Bruggmanniella sp. on host leaves of L. acuminata was examined to investigate the relationship between this gall and its host leaves [23]. Our field observations revealed that Bruggmanniella larvae hatch from eggs in the spring, mine directly into leaf tissues, and remain undeveloped until fall. Galls then begin to develop around October and mature soon thereafter. The larvae develop into second and third instars within mature galls and emerge in early spring of the following year.

Little study has been done on the photosynthetic characteristics of gall midges and their relationship to the photosynthetic biochemical mechanisms of galls. In this study, we investigated the effects of galling by a midge on $L$. acuminata by measuring chlorophyll fluorescence, photosynthetic capacity, ultrastructural morphology, and biochemical composition of the gall and the host leaf.

\section{Results}

\section{Photosynthetic pigments}

Host plant leaves and their galls have different $\mathrm{Car} / \mathrm{Chl}$ ratios in addition to great differences in $\mathrm{Chl}$ and $\mathrm{Car}$ content (Table 1). While galled or gall-free leaves contained around 2,000 and 1,000 $\mu \mathrm{g} / \mathrm{g} \mathrm{DW}$ of Chl and Car, respectively, and gall levels were reduced to 39 and $21 \mu \mathrm{g} / \mathrm{g}$ DW, respectively. That is, both the Chl and Car content of galls are only $\sim 2 \%$ of the gall-free or galled leaves. While all the $\mathrm{Chl} \mathrm{a} / \mathrm{b}$ ratios of galls, and galled and gall-free leaves were the same $(\sim 2.7)$, the $\mathrm{Car} / \mathrm{Chl}$ ratios were significantly different between galls and galled or gall-free leaves, the former being 0.54 and the latter 0.47 . 
Table 1 Chlorophyll and carotenoid content in mature galls and two types of host leaves $(n=4)$

\begin{tabular}{lllll}
\hline & Chl a $+\mathbf{b}(\boldsymbol{\mu g} / \mathbf{g ~ D W})$ & $\mathbf{C h l ~ a / b}$ & Car $(\boldsymbol{\mu g} / \mathbf{g ~ D W})$ & Car/Chl \\
\hline Gall-free leaves & $2138.8 \pm 215.3^{\mathrm{a}}$ & $2.68 \pm 0.4^{\mathrm{a}}$ & $1003.9 \pm 78.0^{\mathrm{a}}$ & $0.47 \pm 0.4^{\mathrm{b}}$ \\
Galled leaves & $1985.1 \pm 262.2^{\mathrm{a}}$ & $2.70 \pm 0.4^{\mathrm{a}}$ & $940.3 \pm 120.0^{\mathrm{a}}$ & $0.47 \pm 0.3^{\mathrm{b}}$ \\
Gall & $38.5 \pm 3.8^{\mathrm{b}}$ & $2.74 \pm 0.1^{\mathrm{a}}$ & $20.8 \pm 1.4^{\mathrm{b}}$ & $0.54 \pm 0.2^{\mathrm{a}}$ \\
\hline
\end{tabular}

$\overline{\mathrm{a}, \mathrm{b}}$ Significant difference (one-way ANOVA, Tukey's honest significance difference test at $\mathrm{p}<0.05$ ).

\section{Gas exchange capacity and Fv/Fm}

The light response curves for $\mathrm{CO}_{2}$ assimilation in galls and in the two types of leaves (i.e. galled and gall-free leaves) were determined. The photosynthetic light-saturation and light- saturation point of leaves of L. acuminata was about $100 \mu \mathrm{mol} \mathrm{m}{ }^{-2} \mathrm{~s}^{-1}$ PPFD, respectively. No gas exchange was detected in any tested cup-shaped gall, whereas any type of host leaves exhibited a gas exchange level of $20 \sim$
$40 \mathrm{nmol} \mathrm{g}{ }^{-1} \mathrm{~s}^{-1}$, as expected (Figure 1A). While stomatal conductance was not significantly different between galled and gall-free leaves, in cup-shaped galls it was always zero or close to it (Figure 1B).

\section{Exterior and interior gall surface}

Light microscopy revealed no stomata on the inside surfaces of gall chambers (Figure 2). Scanning electron
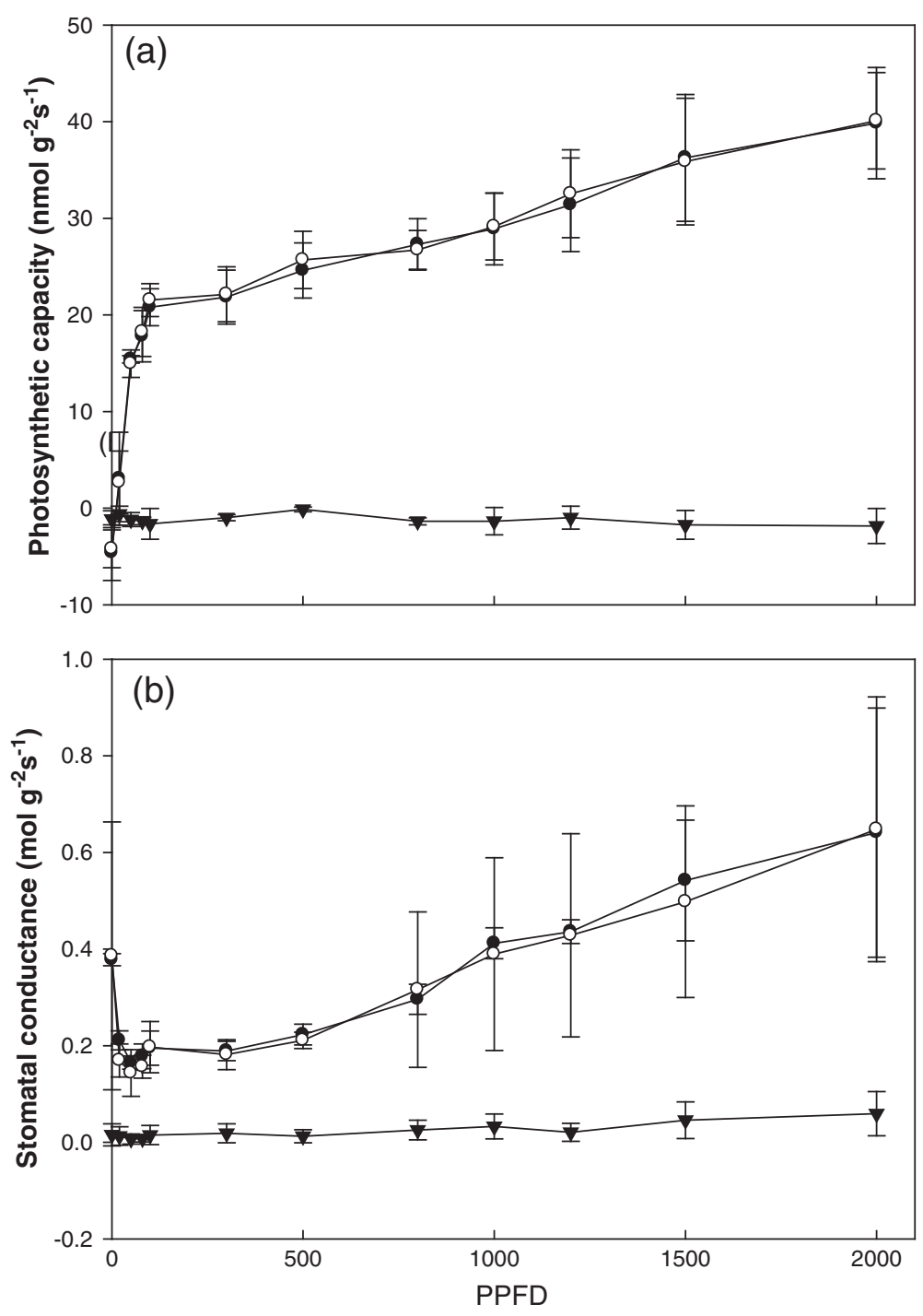

Figure 1 Light response curves. Light response curves for $\mathrm{CO}_{2}$ assimilation (a) and stomatal conductance (b) in gall $(\boldsymbol{\nabla})$, gall-free $(\bullet)$, and galled Litsea acuminate (0), $n=4$. 

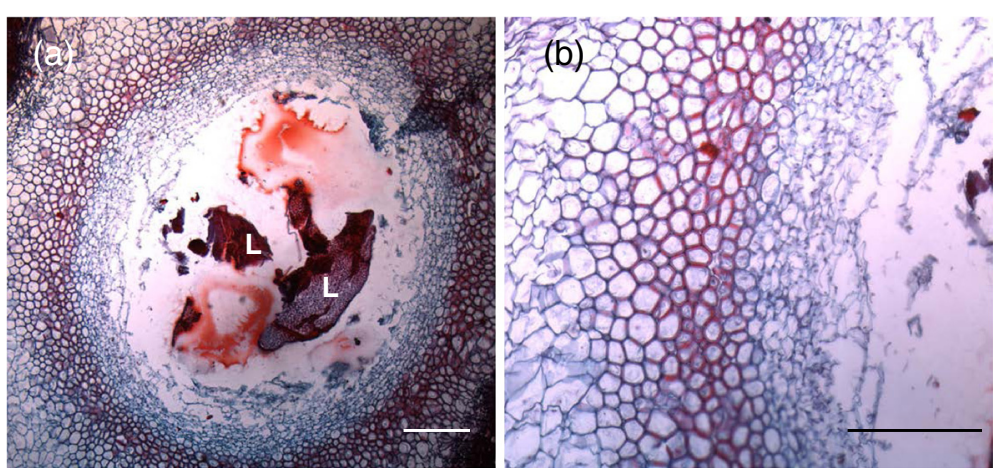

Figure 2 Transverse sections of a cup-shaped gall. (a) Gall chamber with larvae, 40x; (b) inside surface of gall, 100x; L: larvae. Scale bars: $500 \mu \mathrm{m}$.

microscopy of the exterior and interior surfaces of mature cup-shaped galls (Figure 3A and B) revealed no stomata on the outside surfaces of galls; however, their inside surfaces were covered with fungal hyphae (Figure 3B), there were no stomata insides gall tissues either. Trichome and trichome bases were found on exterior surfaces (Figure $3 \mathrm{~A}$ and $\mathrm{C}$ ). The stomata were observed on the abaxial epidermis but not on the adaxial epidermis of galled leaves (Figure 3C and D).

The impact of photosynthetic rates on galls and host leaves

Chlorophyll fluorescence was used to investigate whether the photosynthesis performance of galls and host leaves
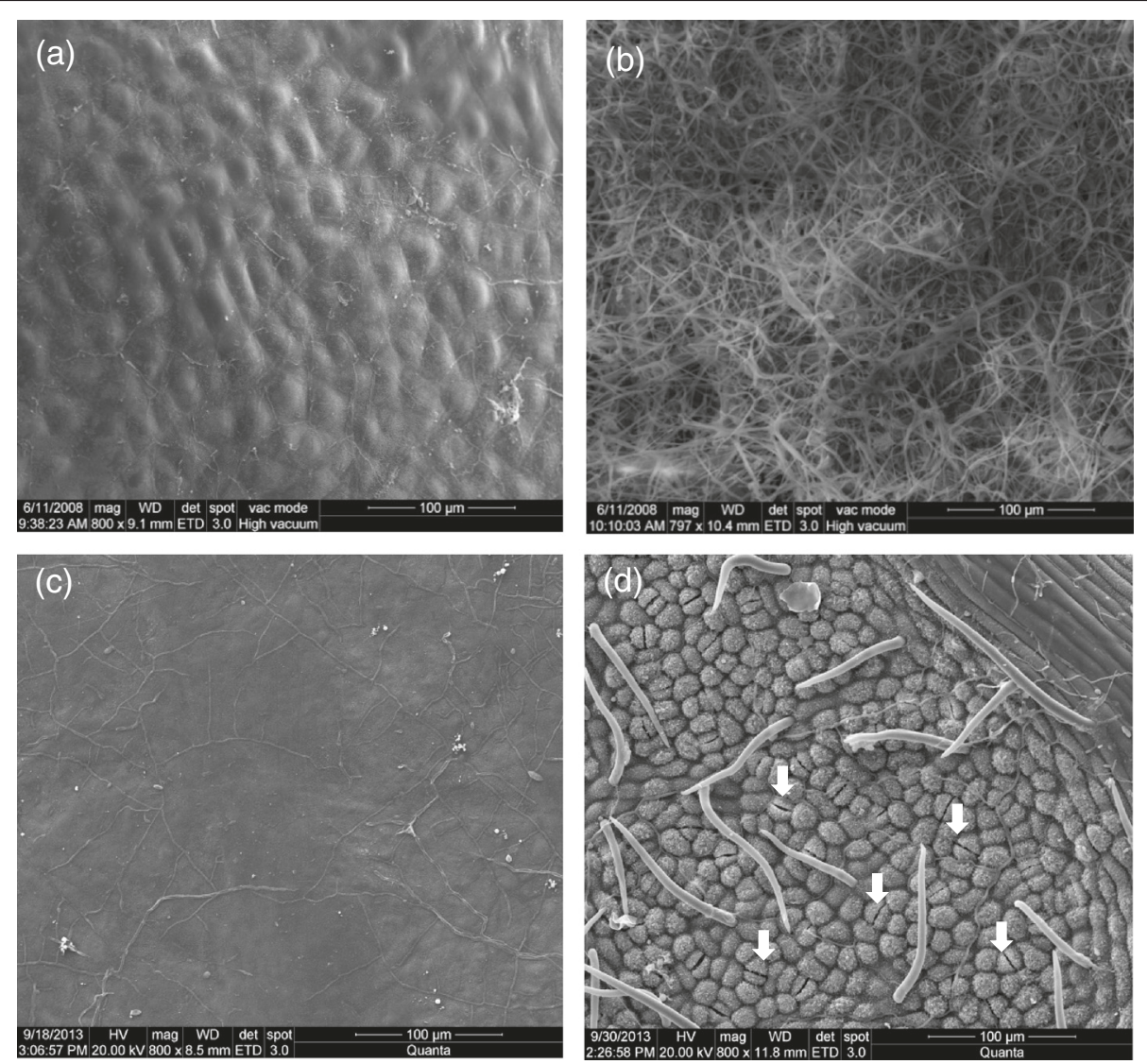

Figure 3 Exterior and interior surface morphology of gall and host. Exterior and interior surface morphology of a cup-shaped gall and host Litsea acuminate. (a) and (b) are exterior and interior surfaces of the gall, respectively; (c) and (d) show the adaxial and abaxial epidermis of a host Litsea acuminate. White arrows show guard cells. 
are different, as the former is cup-like and the latter is flat. No significant difference in Fv/Fm was observed between the two leaf types, indicating that the host leaves' PSII efficiency might not be affected at all by the galling activity of the insect. The values of $\mathrm{Fv} / \mathrm{Fm}$ were significant higher $(10 \%)$ in the two leaf types than in galls (Figure 4).

\section{Confocal imagery of gall chloroplasts}

Confocal laser scanning electron microscopy showed that while chloroplasts were relatively equally distributed in the mesophyll (i.e. palisade or spongy tissues), they were unequally distributed in insect-induced galls (Figure 5A-E). A gradient of chloroplast distribution existed in the galls, as indicated by confocal imagery and integrated optical density (IOD); i.e. outer gall tissues contain the highest density of chloroplasts and inner gall tissues have lower densities or none at all. Chloroplast fluorescence densities of young and mature host leaves were around 22,000 and 55,000 (IOD), respectively, whereas galls always have less than 5,800 (IOD), or none, regardless of whether galls were at early, middle, or later stages of growth (Figure 5F).

\section{Total soluble sugar, starch, free amino acid, and soluble} protein

The total soluble sugar content in galls was three times higher than in the two types of host leaves (Figure 6A). However, starch contents showed no significant differences among galls and their two types of host leaves (Figure 6B). The two types of host leaves showed no significant differences in free amino acids and soluble proteins. However, insect-induced galls contained significantly higher levels of free amino acids, and significantly lower amounts of soluble proteins than the two types of host leaves (Figure 6C and D).

\section{Malondialdehyde (MDA)}

The MDA contents of gall-free, and galled leaves and galls were around 150, 190, and $250 \mathrm{nmol} \mathrm{g}^{-1} \mathrm{FW}$, respectively. All three samples were significantly different from each other (Figure 7). The MDA content of gall was $31 \%$ higher than in galled leaves, and the latter were $26 \%$ higher than in gall-free leaves.

\section{Chloroplast ultrastructure}

Transmission electron microscopy showed that the chloroplasts of $L$. acuminata leaf galls possess a thylakoid morphology with normal stacked grana and are similar to those of other higher plants discussed in the literature (Figure 8). Besides normal grana stacking, mature cupshaped galls have giant starch granules. These observations were ubiquitous during gall development from young to mature stages and from outer to inner layers (data not shown).

\section{Discussion}

Previously, both red ovoid and green obovate galls on Machilus thunbergii (Lauraceae) leaves were found to be seriously deficient in the pigment-protein complexes of PSI and PSII throughout the entire period of gall formation, with a great decrease in carotenoids and chlorophyllrelated compounds $[8,9,24,25]$. The large-scale deficiency in photosynthesis-related proteins and pigments (Table 1) results in incomplete light-harvesting by PSI and PSII on the thylakoid membrane of gall chloroplasts, which in turn indicates that the photosynthetic capacity must be much

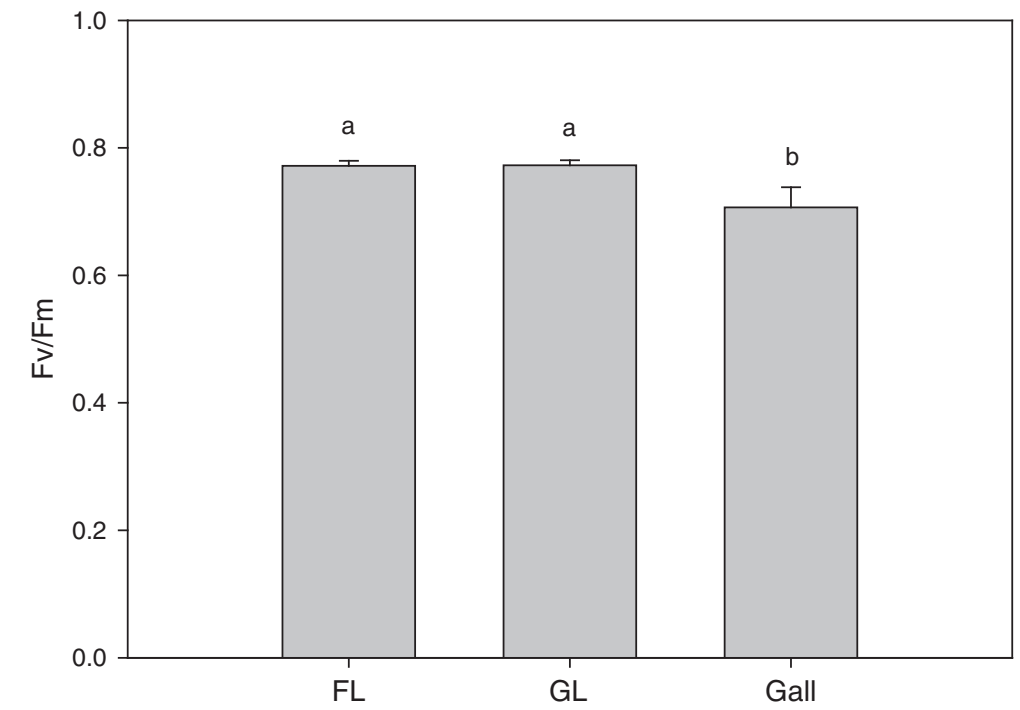

Figure 4 Chlorophyll fluorescence. The impacts of galling by a cecidomyiid on the chlorophyll fluorescence of gall-free (FL) and galled (GL) leaves and the gall of the host Litsea acuminate, $n=4$. 

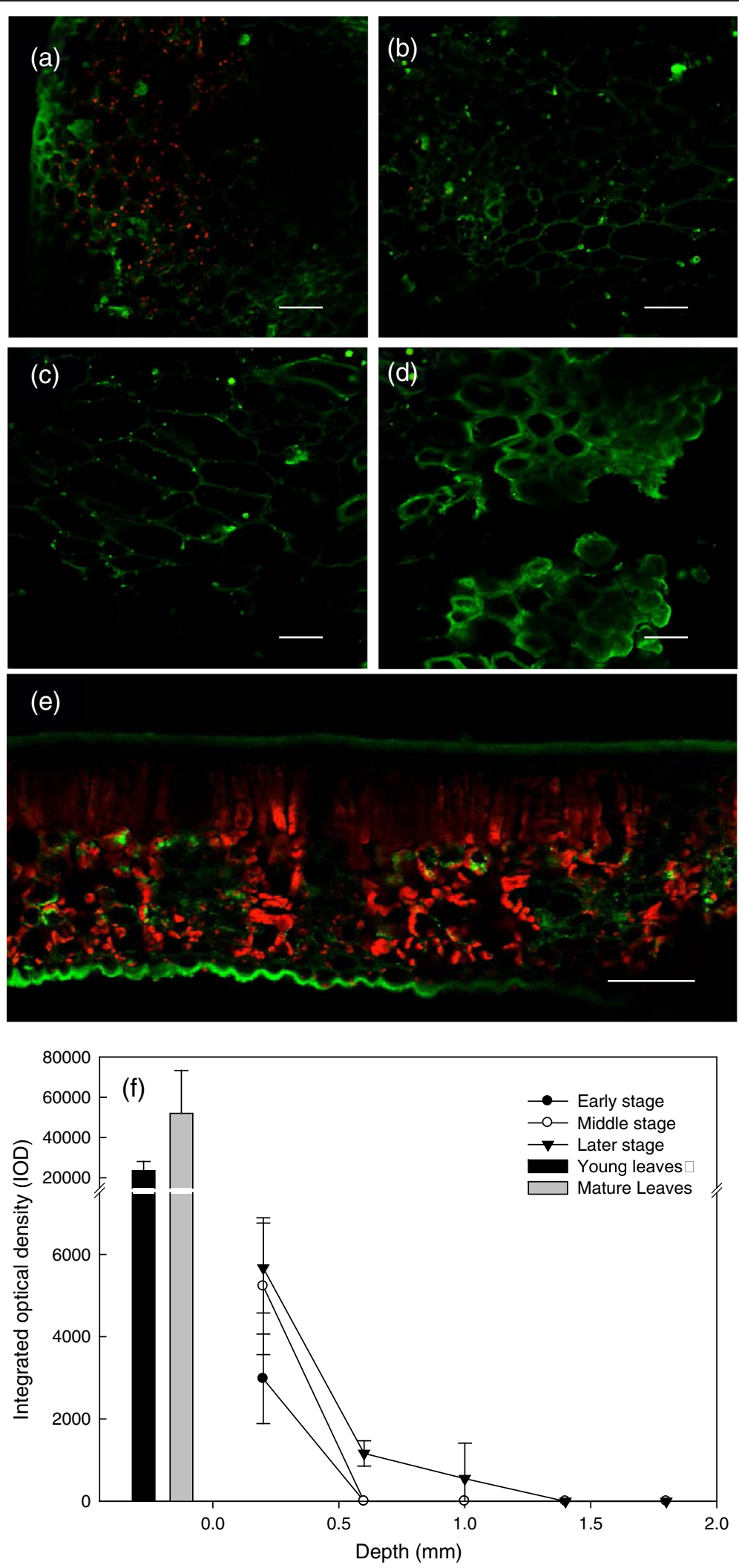

Figure 5 (See legend on next page.) 
(See figure on previous page.)

Figure 5 Confocal images. Confocal imagery of later-stage gall tissues from the outside to the inside of a larval chamber $(\mathbf{a} \sim \mathbf{d})$ and mature leaves (e). The integrated optical density (IOD) of galls and gall-free and galled leaves (f) of the host Litsea acuminata. Data are the averages of thirty samples. Pink fluorescence shows the locations of chloroplasts. Error bars show SD. Scale bars: $100 \mu \mathrm{m}$.

lower in galls than in host leaves, or even that no photosynthesis take place at all (26). These pigment-protein complexes contain either chlorophyll a or both chlorophyll a and b. Both types of pigment-protein complexes also possess several carotenoids that are thought to protect their associated polypeptides from photo-damage. Polypeptides in pigment-protein complexes are thought to orient chlorophyll molecules and perform their light harvesting energy transfer more quickly and efficiently [26].

Gall tissues typically have very low photosynthetic rates [12]. In the present study, no gas-exchange capacity was detected in gall tissues (Figure 1), which is probably due to the lack of stomata on exterior and interior gall surfaces (Figures 2 and 3). These results support the hypothesis that cup-shaped gall tissues serve as sinks of $L$. acuminata leaves as do the red ovoid and green obovate galls on $M$. thunbergii leaves [21].
Dorchin et al. [10] reported that wasp-induced galls may make a substantial contribution to carbon budgets, but gas-exchange in cup-shaped cecidomyiid galls was not detected either in this study or in many other kinds of galls [21]. These results demonstrate that physiological effects may differ among infections associated with different insect species and microenvironments. The significantly lower $\mathrm{Fv} / \mathrm{Fm}$ values of galls relative to leaf surfaces indicates that galls have a much lower PSII energy transduction efficiency than non-infected leaf surface tissues (Figure 4). Furthermore, defects in the chlorophyll protein complexes of PSI and PSII in galls exhibited depressed efficiencies to the reaction centers of both photosystems $[8,9,21]$. Meanwhile, the stimulus of an insect on a host leaf results in a series of reactions in the host leaf, causing a shift from an autotrophic to a heterotrophic status in addition to gall development [21].
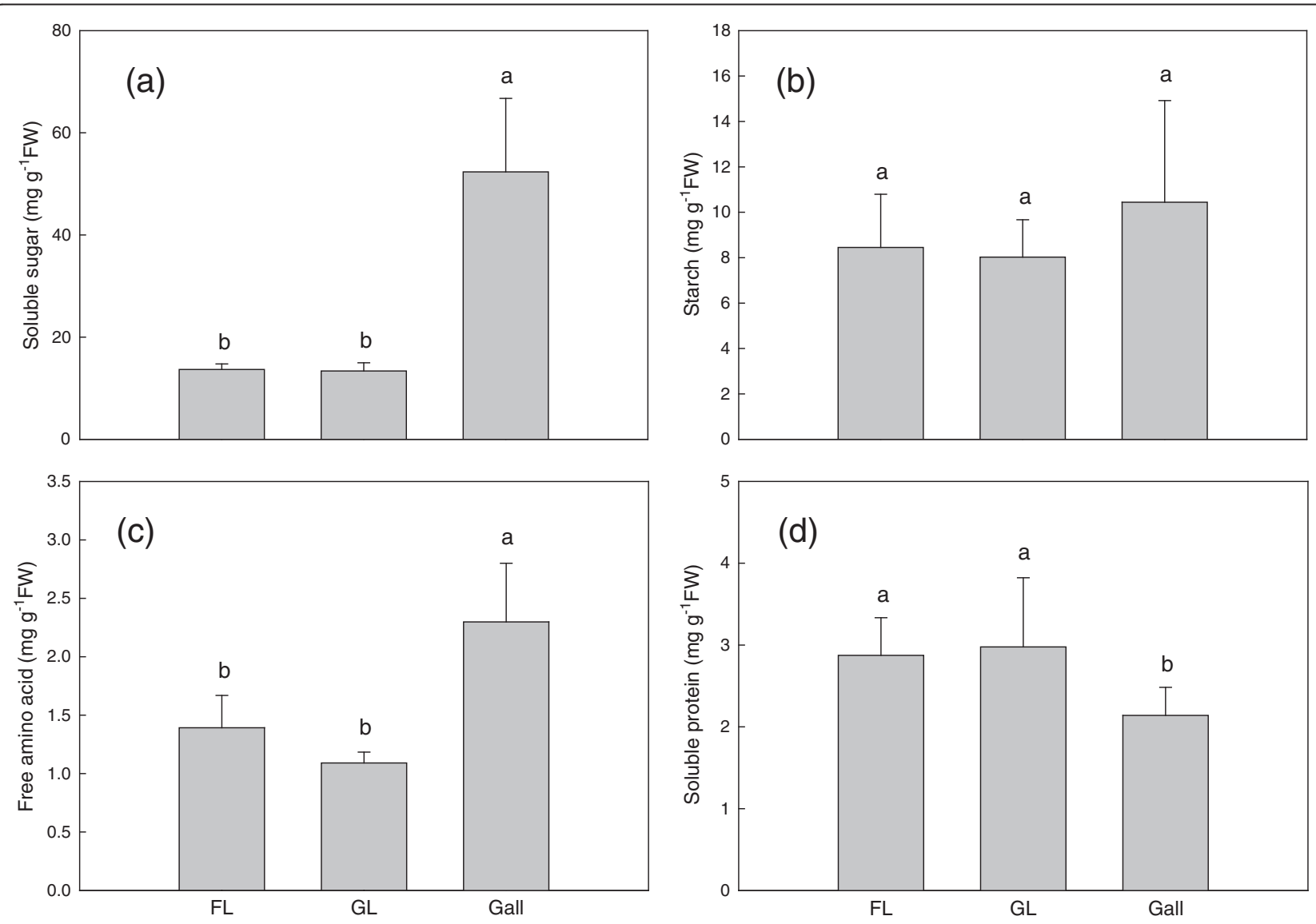

Figure 6 Biochemical compositions. Soluble sugar (a), starch (b), free amino acid (c), and protein (d) contents of gall-free (FL) and galled (GL) Litsea acuminata leaves and galls, $n=8$. 


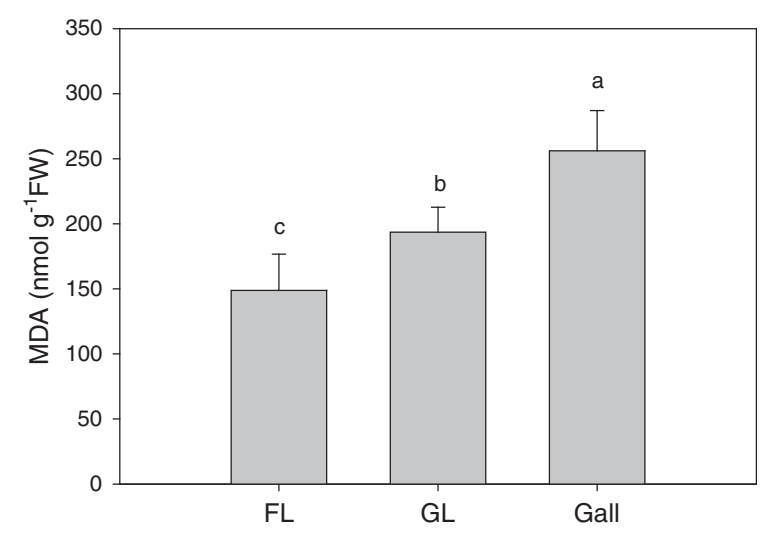

Figure 7 Malonyl dialdehyde (MDA) levels. (FL) gall-free and (GL) galled Litsea acuminate leaves and galls, $\mathrm{n}=8$.

Koyama et al. [27] indicated that the improved performance of Rhopalosiphum insertum was ascribed to increased concentrations of amino acids in galled leaves. Gange and Nice [28] suggested that Urophora cardui gall inhabitants can manipulate $\mathrm{N}$ to an optimal level. Generally, gall tissues contain lower levels of $\mathrm{N}$ than ungalled plant tissues [26,29]. Lower plant $\mathrm{N}$ may have detrimental effects on insect herbivores, however, $\mathrm{N}$ is generally regarded as a crucial limiting nutrient for phytophagous arthropods, and it can increase the production of C-based secondary chemicals such as phenolics and may deter herbivore feeding [30]. These results suggest that any $\mathrm{C}$-related metabolites in leaf tissues may be consumed to strengthen defense mechanisms against gall infections. Moreover, low levels of $\mathrm{C}$ and $\mathrm{N}$ may be an effect of the low levels of carotenoids and chlorophyllrelated compounds in chlorophyll biosynthesis and degradation pathways. It could also be a result of low levels of photosynthesis-related proteins like RuBisCo in the stroma and light-harvesting protein complexes of the two photosystems on the thylakoid membrane and their corresponding mRNAs in galls $[8,9,21,25,31]$. It is known that RuBisCo and light-harvesting protein complexes comprise more than half of the stroma and thylakoid proteins in normal chloroplasts, respectively [26]. However, Hartley and Lawton [32] concluded that cynipid gall-formers may manipulate host $\mathrm{N}$ levels to their own advantage by preventing an increase in gall $\mathrm{N}$ levels in fertilized trees, and such an increase would reduce insect survival rates.

The efficiency of $\mathrm{Fv} / \mathrm{Fm}$ in leaves was slightly affected by the galling activity (Figure 4) and the extent of its infection or gall number per leaves [33]. Retuerto et al. [17] reported that PSII (indicated by $\mathrm{Fv} / \mathrm{Fm}$ ) in galled leaves on holly trees was increased compared to gall-free leaves, and predicted that scale insects would increase photosynthesis. However, in our study, the values of $\mathrm{Fv} /$ Fm were not significantly different between galled and gall-free leaves, which agrees with the results of Aldea et al. [11] and Huang et al. [21].

A gradient of chloroplast distribution in terms of chloroplast number and fluorescence intensity was found in the cup-shaped galls of L. acuminata leaves (Figure 5), and in red ovoid and green obovate galls of $M$. thunbergii leaves (data not shown). Chloroplasts and fluorescence intensity were similar throughout mesophyll tissues. Chloroplasts were most abundant in outer gall tissues and least abundant (or absent) in inner gall tissues, which is further evidence that the highest photosynthetic capacity occurs in galls outer tissues (i.e. more autotrophic) and the lowest near the gall chamber (i.e. more heterotrophic).

Galls are reported to have significantly higher levels of soluble carbohydrates than leaves [34], and soluble sugar are higher in leaf blades of the European chestnut while galls are richer in starch [14]. In this study, gall tissues had much higher total soluble sugar levels than leaves

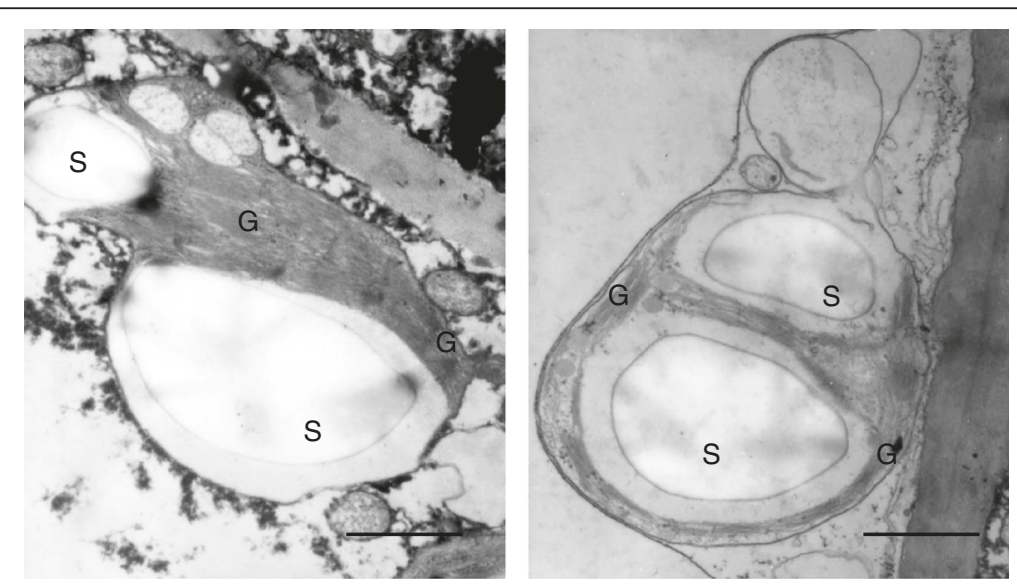

Figure 8 Ultrastructural morphology of chloroplasts in galls. Ultrastructural morphology of chloroplasts in galls on a host Litsea acuminata leaf. S, starch; G, grana. Scale bar: $1 \mu \mathrm{m}$. 


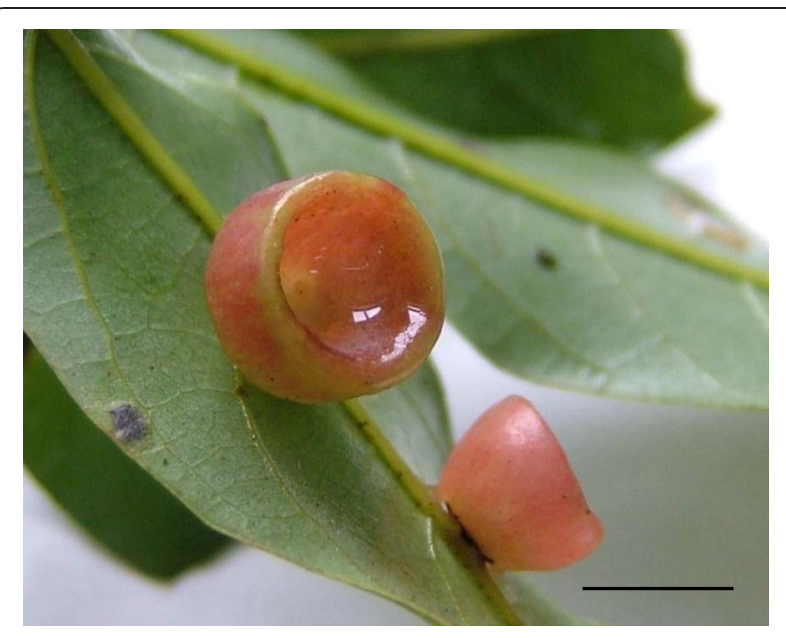

Figure 9 Morphology of cup-shaped galls. Morphology of cup-shaped galls induced by Bruggmanniella sp. on host leaves of Litsea acuminata. Galls reside on the lower epidermal midrib or vein of host leaves. Scale bars: $1 \mathrm{~cm}$.

(Figure 6), suggestive of a translocation of carbohydrates from leaves to galls, since the photosynthetic capacity of galls is much lower than that of the host leaves. Similar levels of starch in galls and host leaves can be caused either by high metabolic activity or by translocation of nutrients to galls [20,24]. The highest content of total soluble sugars in galls should indicate that the intake of carbohydrates is necessary as a nutrition source for galls. High concentrations of total soluble sugars in tissues of galls, together with the lower energy transduction efficiency of PSII, confirms that galls are sinks for host leaf photoassimilates $[24,35]$. Our present and previous results [20] support this hypothesis and agree with the findings of Bronner [3], Motta et al. [34], and Castro et al. [24].

The MDA content in the cup-shaped gall is around $31 \%$ higher than in the galled host leaf, which is around $26 \%$ higher than in the gall-free leaf (Figure 7). Our data strongly suggest that the gall-inducing insect significantly affected the lipid composition of the host leaf in plasma membrane level, and that the lipids of the cupshaped gall are under higher oxidative stress than in the galled leaf, which in turn is under higher oxidative stress than in the gall-free leaf. The oxygen concentration in gall tissues is much lower than in galled or gall-free leaves [18], but gall tissues face higher oxidative stressing than host leaves. However, galls produce more secondary metabolites such as polyphenols, anthocyanins, flavanoids, and tannins $[8,9]$ to strengthen the galls antioxidative capacity for counteracting higher oxidative stresses [36].

Cup-shaped galls contain giant starch granules and normal stacked grana (Figure 8). In this study, no stomata were found on exterior and interior gall surfaces nor was gas exchange detected on exterior gall surfaces.
Therefore, it is possible that the photoassimilates of gall chloroplasts might be barely enough to support the galls, and the nutrition required by the larvae in the gall chamber might be translocated directly or indirectly from the host leaves. If so, $\mathrm{CO}_{2}$ and $\mathrm{O}_{2}$ cycling could be micro-environmentally self-balancing between mitochondria and chloroplasts in gall tissues. Since interior gall surfaces contain no effective stomata, it is perplexing how larvae in galls exchange $\mathrm{CO}_{2}$ and $\mathrm{O}_{2}$ over a period of more than ten months from oviposition to eclosion. One possibility is that gas exchange among gall, larvae, and fungi and for gall photosynthesis is via diffusion of $\mathrm{CO}_{2}$ and $\mathrm{O}_{2}$ through the gall's innermost layer and the intercellular spaces of the inner tissue layers (Figure 2); that is, gas exchange can still take place via diffusion even though the internal surface is totally or partially covered by fungal hyphae [18].

Two kinds of food chains among larvae, galls, and leaves could exist in nature, depending on whether fungi occur inside galls. First, since abundant fungi grow inside the cup-shaped galls on L. acuminata leaves (Figure 3B) and the red ovoid and green galls on $M$. thunbergii leaves [20], it is possible that a micro-environmental food chain is generated as follows: host leaves $\rightarrow$ galls $\rightarrow$ fungi $\rightarrow$ larvae. The second possible food chain is host leaves $\rightarrow$ galls $\rightarrow$ larvae if the inside of the galls have no fungi and no stomata as in the ball-shaped or globular galls induced by Trioza shuiliensis (Yang) on Machilus japonica (data not shown). This question is currently under investigation by our group.

Many chlorophyll-deficient mutants have been reported in barley, pea, maize, wheat, sweet clover, rice, soybean, sugar beet, Arabidopsis thaliana, Chlamydomonas, variegated plants, and other plants. Except for several cases, all chlorophyll-deficient mutants reveal reductions in chlorophyll content, higher ratios of chlorophyll a/b, immature ultrastructures in the thylakoid membrane, marked changes in pigment-protein complexes, and a general sensitivity to temperature, light intensity, and photoperiod [37]. Mungbean testa [38] and insect-induced galls, both are deficient in pigment-protein complexes of PSI and PSII, can be recognized either as a chlorophyll-deficient mutation of the leaf or a non-leaf green tissue with abnormal morphology. The insect attack causes a transformation from a flat leaf to a cup-shaped gall with varying appearance and color. However, while chlorophyll a/b ratios of insect-induced galls and mungbean testa are below the average $(2.5 \sim 3.0)$ for leaves, the ratios for chlorophyll-deficient mutants are between 4 and $\infty$ [37]. The incomplete organization of PSI and PSII may affect gall photosynthesis light-harvesting, energy transfer, and photochemical energy conversion performed in pigment-protein complexes. 


\section{Conclusions}

All the current evidence indicates that galling cecidomyiid Bruggmanniella sp. insects transform the photoassimilative abilities of $L$. acuminata and $M$. thunbergii leaves into gall sinks. This is strongly indicated in the present study because there is (1) no stomata in gall external and internal surfaces, (2) no gas exchange in the external surfaces of galls, and (3) a great increase in soluble sugars in galls. This conclusion is supported by other authors that have noted (1) a great reduction in carotenoids and chlorophyllrelated compounds, (2) a deficiency in pigment-protein complexes and incomplete light-harvesting antennae in PSI and PSII supramolecules, (3) insect-induced cecidomyiid galls deficient in light-harvesting protein complex II showing normal grana stacking, and (4) a great reduction in secondary metabolites like anthocyanins and tannins $[8,9,20,24,31,39]$. In short, leaf-derived cecidomyiid galls are novel sinks in $L$. acuminata leaves. Insect-induced galls may be a new organ that is mostly heterotrophic but still retains an autotrophic function. The ratio between heterotrophy and autotrophy in galls requires further exploration.

\section{Methods}

\section{Plants and galls}

Cup-shaped galls (Figure 9) induced by an unidentified gall midge on Litsea acuminata were collected from $800 \mathrm{~m}$ asl in the Mt. Datun region, Yangmingshan National Park (approximately 11,455 hectares, 200 to 1,120 meters asl) located in the north-western part of Taipei, Taiwan. The gall usually takes about four months to develop from oviposition to maturity. The gall is pink or light-green and its center is concave, looking like a crystallite cup or bowl (Table 1). We sampled trees for cupshaped galls and collected data from gall-infected and non-galled leaves in the early spring (February and March) of 2009-2011 when galls were mature. Tissues of cup-shaped galls, galled leaves (GL), and gall-free leaves (FL) were examined. Samples were kept on ice until sampling was finished. Galls were dissected to separate larvae from plant tissues and fixed for confocal imagery microscopy and scanning and transmission electron microscopy. Dissected galls were lyophilized, and stored at $-20^{\circ} \mathrm{C}$ until analysis.

\section{Pigment analysis}

Mature leaves and galls were frozen with liquid nitrogen and then extracted with $80 \%$ acetone. The concentrations of chlorophyll and carotenoids (Car) were determined according to a combined procedure described by Yang et al. [40].

\section{Photosynthetic capacity and chlorophyll fluorescence}

Chlorophyll fluorescence was detected (for $20 \mathrm{~min}$ with leaf clips) at dawn on dark-adapted galls and uninfected tissues of the same leaf at room temperature with a Pocket Plant Efficiency Analyzer (Hansatech, U.K.). The maximum quantum efficiency of PSII $(\mathrm{Fv} / \mathrm{Fm})$ was calculated from $(\mathrm{Fm}-\mathrm{Fo}) / \mathrm{Fm}$, where $\mathrm{Fo}, \mathrm{Fm}$, and $\mathrm{Fv}$ are ground fluorescence, maximum fluorescence of the dark-adapted subjects, and maximum variable fluorescence, respectively [41]. The light response curves of photosynthesis were measured with a portable, openflow gas exchange system connected to a leaf chamber and LED light source (model 6400, LI-COR, CA, USA). Photosynthetic capacity was measured at saturating light intensities under $800 \mu \mathrm{mol} \mathrm{m}{ }^{-2} \mathrm{~s}^{-1}$ photosynthetic photon flux density (PPFD) at ambient temperature. All measurements were taken before 11:00 a.m. to avoid the midday depression in photosynthesis. Fluorometer dark leaf clips were circular with diameters of $5.5 \mathrm{~mm}$, which are considerably smaller than the typical gall diameter of $8-20 \mathrm{~mm}$. Gas exchange was measured with a $6 \mathrm{~cm}^{2} \mathrm{cu}-$ vette. The area surrounding the gall was sealed with black tape to ensure that the measurement of gas exchange was solely from the gall and excluded the effects of ungalled leaf tissues. Chlorophyll fluorescence and photosynthetic rates of galls and host leaves (FL and GL) were then examined.

\section{Light microscopy}

Galls and leaves of the host plant were cleaned and fixed in FAA solution (formalin, acetic acid, 50\% ethanol; 1:1:18) for 24-48 h. Fixed samples were gradually dehydrated in an ethanol series, slowly infiltrated and embedded in paraffin, and then sectioned on a manual rotary microtome (American Optical 820, Leica, USA) using a razor blade. The $15 \mu \mathrm{m}$ thick sections were examined using a light microscope (Leitz Laborlux S, Leitz, German).

\section{Scanning electron microscopy}

Detached young and mature galls, and mature leaves were fixed for at least $3 \mathrm{~h}$ in $2.5 \%$ glutaraldehyde and then washed three times with $0.1 \mathrm{M}$ phosphate buffer. Each wash took $15 \mathrm{~min}$. A series of ethanol mixtures (30, 50, 75, 90, and $100 \%)$ were used to dehydrate fixed samples followed by $100 \%$ acetone. A thin gold film was set on the sample's surface [42]. The morphology of the gall epidermis was examined with a Zeiss DSM 950 scanning electron microscope.

\section{Transmission electron microscopy}

The inner parts of galls were collected, cut into small cubes, and placed in fixation solution containing 2.5\% glutaraldehyde and $4 \%$ paraformaldehyde in $0.1 \mathrm{M}$ sodium phosphate buffer ( $\mathrm{pH}$ 7.0) in the field. The samples were 
washed three 20 -min rinses, post-fixed in $1 \%$ osmium tetroxide for $2 \mathrm{~h}$, dehydrated through an ethanol series, infiltrated and embedded in Spurr's resin [43], and then polymerized at $70^{\circ} \mathrm{C}$ for $8 \mathrm{~h}$. The ultrathin sections $(70-90 \mathrm{~nm})$ were collected and stained with ethanol uranyl acetate and lead citrate. Thylakoid morphology was observed with a Philips CM 100 transmission electron microscope at $75 \mathrm{kV}$.

\section{Confocal laser scanning electron microscopy}

Hand-cut sections of leaves and galls were placed on slides in distilled water. Photographic images were captured with a Zeiss LSM510 Meta confocal microscope with a Plan-Apochromat $20 \times / 0.6$ objective. Specimens were excited by an $8 \%$ Argon $488 \mathrm{~nm}$ laser and emission signals were detected by a photon multiplier tube (Main beam splitter: HFT 488; beam splitter 1: Mirror; beam splitter 2: NFT 545; BP 650-710 IR, Zeiss, Germany). Chlorophyll red auto-fluorescence indicated chloroplast localization. Confocal images were analyzed by ImagePro Plus software (Medica Cybernetics, USA). Colorcube-based segmentation was used to select only those shades of red that were in the area of interest. The integrated optical density (IOD) of red staining was measured and indicated a positive correlation to chlorophyll fluorescence intensity.

\section{Total soluble sugars and free amino acids}

Samples (0.2 g fresh weight) were placed into a $15 \mathrm{~mL}$ tube and then $5 \mathrm{~mL}$ of distilled water was added and mixed in. The supernatant was collected after $30 \mathrm{~min}$ in a water bath at $85^{\circ} \mathrm{C}$. This step was repeated once and then distilled water was added to obtain $10 \mathrm{~mL}$ of the collected extract. The soluble sugar content was then determined using the sulfuric acid anthrone method [44] at a wavelength of $630 \mathrm{~nm}$ and the free amino acid content was determined using the ninhydrin method [45] at a wavelength of $570 \mathrm{~nm}$.

\section{Starch content}

Starch was extracted according to the method of Takahashi et al. [46]. The residue obtained from distilled-water extraction was dried and added to $1 \mathrm{~mL}$ of distilled water. This mixture was placed in a water bath for $30 \mathrm{~min}$ at $100^{\circ} \mathrm{C}$. The resulting gelatinized starch was digested after cooling with $1 \mathrm{~mL}$ $9.2 \mathrm{~N}$ perchloric acid for $10 \mathrm{~min}$. Two milliliters of distilled water was added and the mixture was centrifuged at $8,000 \mathrm{~g}$ for $6 \mathrm{~min}$. After the extract was transferred to a $15 \mathrm{~mL}$ tube, $1 \mathrm{~mL}$ of $4.6 \mathrm{~N}$ perchloric acid was added and stirred for $10 \mathrm{~min}$. Three milliliters of distilled water were added to the final volume after centrifugation. Starch contents were determined using the same method as for soluble sugars.

\section{Soluble protein content}

Total protein was measured using the method of Bradford [47]. Samples (0.2 g fresh weight) were ground up in mortar with liquid nitrogen, to which $3 \mathrm{~mL}$ of a phosphate buffered solution ( $\mathrm{pH} 7.0)$ was added. The extract was centrifuged at $13,000 \mathrm{~g}$ for $15 \mathrm{~min}$ at $4^{\circ} \mathrm{C}$ and $0.1 \mathrm{~mL}$ of the supernatant was combined with $4.9 \mathrm{~mL}$ of Coomassie brilliant blue G-250 solution $\left(0.1 \mathrm{~g} \mathrm{~L}^{-1}\right)$. The soluble protein content was determined after $2 \mathrm{~min}$ at a wavelength of $595 \mathrm{~nm}$.

\section{Lipid peroxidation}

To measure the malondialhyde (MDA) content, fresh samples $(0.2 \mathrm{~g})$ were ground in a cold mortar containing $1.8 \mathrm{ml}$ of $5 \%$ trichloroacetic acid. After centrifugation at $10,000 \mathrm{~g}$ for $5 \mathrm{~min}$ at $20^{\circ} \mathrm{C}, 1 \mathrm{ml}$ of supernatant with $4 \mathrm{ml}$ of $0.5 \%$ thiobarbituric acid reagent $(0.5 \%[\mathrm{~m} / \mathrm{v}]$ thiobarbituric acid dissolved in $20 \%[\mathrm{~m} / \mathrm{v}]$ trichloroacetic acid) was mixed in, heated at $95^{\circ} \mathrm{C}$ for $30 \mathrm{~min}$, and then quickly cooled and centrifuged at 2,000 $\mathrm{g}$ for $10 \mathrm{~min}$. Absorbance was determined at 532 and $600 \mathrm{~nm}$. The MDA content was computed using a standard curve relating MDA concentrations to absorbance [48].

\section{Statistical analysis}

Differences in photosynthetic parameters among tissues were examined using a completely randomized analysis of variance. For significant values, means were separated by Tukey's honest significance difference test at $p<0.05$. Relationships between parameters were examined using simple linear regression models. All statistical analyses were conducted using JMP software, version 5.01 (SAS Institute, Cary, NC).

\section{Abbreviations}

$\mathrm{C}$ : Carbon; N: Nitrogen; $\mathrm{CO}_{2}$ : Carbon dioxide; $\mathrm{O}_{2}$ : Oxygen; PS: Photosystem; Fo: Background fluorescence; Fm: Maximum dark-adapted fluorescence; Fv: Maximum variable fluorescence; GL: Galled leaves; FL: Gall-free leaves; MDA: Malondialdehyde; LED: Light emitting diode; PPFD: Photosynthetic photon flux density.

\section{Competing interests}

The authors declare that they have no competing interests.

\section{Authors' contributions}

MYH, YTC, CMY conceived and designed the experiments. MYH, WDH, HMC, CCC, PJC performed the experiments. MYH and WDH analyzed the data. MYH, YTC and CMY wrote the manuscript. All authors read and approved the final manuscript.

\section{Acknowledgements}

The authors thank Dr. Man-Miao Yang (Department of Entomology, National Chung-Hsing University) for insightful comments on the experiments and Mrs. Mei-Jane Fang (Institute of Plant and Microbial Biology, Academia Sinica) for confocal laser scanning microscopy.

\section{Author details}

'Department of Horticulture and Biotechnology, Chinese Culture University, Taipei 111 Hsulin, Taiwan. ${ }^{2}$ Department of Agronomy, National Taiwan University, Taipei 106Daan, Taiwan. ${ }^{3}$ Department of Biotechnology and Pharmaceutical Technology, Yuanpei University of Medical Technology, 
Hsinchu 300, Taiwan. ${ }^{4}$ Miaoli District Agricultural Research and Extension Station, COA, Guannan, Kungkuan 363Miaoli County, Taiwan. ${ }^{5}$ Department of Life Science, National Taiwan Normal University, Taipei 116Wenshan, Taiwan. ${ }^{6}$ Biodiversity Research Center, Academia Sinica, Taipei 115Nankang, Taiwan.

\section{Received: 19 May 2014 Accepted: 30 January 2015}

\section{Published online: 21 February 2015}

\section{References}

1. Stone GN, Schönrogge $K$. The adaptive significance of insect gall morphology. Trends Ecol Evol. 2003;18:512-22.

2. Rohfritsch $\mathrm{O}$. Food supply mechanism related to gall structure, the example of Geocrypta galii Lw. (Cecidomyiidae, Oligotrophini) on Galium mollugo. Phytophaga. 1988;2:1-17.

3. Bronner $\mathrm{R}$. The role of nutritive cells in the nutrition of cynipids and cecidomyiids. In: Shorthouse JD, Rohfritsch O, editors. Biology of insect-induced galls. Oxford: University Press; 1992. p. 118-40.

4. Dreger-Jauffret F, Shorthouse JD. Diversity of gall-inducing insects and their galls. In: Shorthouse JD, Rohfritsch O, editors. Biology of insect-induced galls. Oxford: University Press; 1992. p. 8-33.

5. Raman A, Dhileepan K. Qualitative evaluation of damage by Epiblema strenuana (Lepidoptera: Tortricidae) to the weed Parthenium hysterophorus (Asteraceae). Ann Entomol Soc Am. 1999;92:717-23.

6. Larson KC, Whitham TG. Manipulation of food resources by a gall-forming aphid: the physiology of source-sink interactions. Oecologia. 1991;88:15-21.

7. Raman A, Abrahamson WG. Morphometric relationships and energy allocation in the apical rosette galls of Solidago altissima (Asteraceae) induced by Rhopalomyia solidaginis (Diptera: Cecidomyiidae). Environ Entomol. 1995:24:635-9.

8. Yang CM, Yang MM, Hsu JM, Jane WN. Herbivorous insect causes deficiency of pigment-protein complexes in an oval-pointed cecidomyiid gall of Machilus thunbergii leaf. Bot Bull Acad Sin. 2003;44:315-21.

9. Yang CM, Yang MM, Huang MY, Hsu JM, Jane WN. Life time deficiency of photosynthetic pigment-protein complexes $C P 1, A 1, A B 1$, and $A B 2$ in two cecidomyiid galls derived from Machilus thunbergii leaves. Photosynthetica. 2007:45:589-93.

10. Dorchin N, Cramer MD, Hoffmann JH. Photosynthesis and sink activity of wasp-induced galls in Acacia pycnantha. Ecol. 2006;87:1781-91.

11. Aldea M, Hamilton JG, Resti JP, Zangerl AR, Berenbaum MR, Frank TD, et al. Comparison of photosynthetic damage from arthropod herbivory and pathogen infection in understory hardwood saplings. Oecologia. 2006;149:221-32.

12. Larson KC. The impact of two gall-forming arthropods on the photosynthetic rates of their hosts. Oecologia. 1998;115:161-6.

13. Florentine SK, Raman A, Dhileepan K. Effects of gall induction by Epiblema strenuana on gas exchange, nutrients, and energetics in Parthenium hysterophorus. Biocontrol. 2005;50:787-801.

14. Ugolini F, Massetti L, Pedrazzoli F, Tognetti R, Vecchione A, Zulini L, et al. Ecophysiological responses and vulnerability to other pathologies in European chestnut coppices, heavily infested by the Asian chestnut gall wasp. Forest Ecol Manag. 2014;314:38-49.

15. Patankar R, Thomas SC, Smith SM. A gall-inducing arthropod drives declines in canopy tree photosynthesis. Oecologia. 2011;167:701-9.

16. Fay PA, Hartnett DC, Knapp AK. Plant tolerance of gall-insect attack and gall-insect performance. Ecol. 1996;77:521-34.

17. Retuerto R, Fernandez-Lema B, Rodriguez-Roiloa S, Obeso JR. Increased photosynthetic performance in holly trees infested by scale insects. Funct Ecol. 2004;18:664-9.

18. Nabity PD, Miranda MJ, Berenbaum MR, Delucia EH. Leaf-galling phylloxera on grapes reprograms host metabolism and morphology. Proc Natl Acad Sci U S A. 2013;110:16663-8.

19. Haiden SA, Hoffmann JH, Cramer MD. Benefits of photosynthesis for insects in galls. Oecologia. 2012;170:987-97.

20. Joy JB. Symbiosis catalyses niche expansion and diversification. Proc R Soc B. 2013;280:20122820.

21. Huang MY, Huang WD, Chou HM, Lin KH, Chen CC, Chen PJ, et al. The leaf-derived cecidomyiid galls are sinks in Machilus thunbergii (Lauraceae) leaves. Physiol Plantarum. 2014;152:475-85.

22. Heath JJ, Stireman III JO. Dissecting the association between a gall midge, Asteromyia carbonifera, and its symbiotic fungus, Botryosphaeria dothidea. Entomol Exp Appl. 2010;137:36-49.
23. Lin SF. Biosystematics of the cecidomyiid forming polymorphic galls on the leaves of Litsea accuminata (BI.) Kurata. Master thesis. National Chung Hsing University, Department of Entomology; 2011.

24. Huang MY, Huang WD, Chou HM, Chen CC, Chang YT, Yang CM. Herbivorous insects alter the chlorophyll metabolism of galls on host plants. J Asia-Pacific Entomol. 2014;17:431-4

25. Castro AC, Oliveira DC, Moreira ASFP, Lemos-Filho JP, Isaias RMS. Source-sink relationship and photosynthesis in the horn-shaped gall and its host plant Copaifera langsdorffii Desf. (Fabaceae). S Afr J Bot. 2012;83:121-6.

26. Albertsson PA, Andreasson E, Svensson P. The domain organization of plant thylakoid membrane. FEBS Lett. 1990;273:36-40.

27. Koyama Y, Yao I, Akimoto SI. Aphid galls accumulate high concentrations of amino acids: a support for the nutrition hypothesis for gall formation. Entomol Exp Appl. 2004;113:35-44.

28. Gange A, Nice HE. Performance of the thistle gall fly, Urophora cardui, in relation to host plant nitrogen and mycorrhizal colonization. New Phytol. 1997; 137:335-43.

29. Hartley SE. The chemical composition of plant galls: are levels of nutrients and secondary compounds controlled by the gall-former? Oecologia. 1998;113:492-501.

30. Kampichler C, Teschner M, Klein S, Körner C. Effects of 4 years of $\mathrm{CO} 2$ enrichment on the abundance of leaf-gall and leaf-mines in mature oaks. Acta Oecologia. 2008;34:139-46.

31. Huang MY, Lin KH, Yang MM, Chou HM, Yang CM, Chang YT. Chlorophyll fluorescence, spectral properties, and pigment composition of galls on leaves of Machilus thunbergii. Int J Plant Sci. 2011;172:323-9.

32. Hartley SE, Lawton JH. Host-plant manipulation by gall-insects: a test of the nutrition hypothesis. J Anim Ecol. 1992;61:113-9.

33. Huang MY, Chou HM, Chang YT, Yang CM. The number of cecidomyiid insect galls affects the photosynthesis of Machilus thunbergii host leaves. J Asia-Pacific Entomol. 2014;17:151-4.

34. Motta LB, Kraus JE, Salatino A, Salatino MLF. Distribution of metabolites in galled and non-galled foliar tissues of Tibouchina pulchra. Biochem Syst Ecol. 2005;33:971-81.

35. Ito M. Effect of gall formation by a cynipid wasp, Andricus symbioticus, on the development of the leaves and shoots of Quercus dentate. Entomol Sci. 2005;8:229-34.

36. Huang MY, Hsu MH, Huang WD, Chen PJ, Yang MM, Chang YT, et al. Differential contribution of antioxidants to antioxidative functions in galls evaluated by grey system theory. J Grey Sys. 2012;4:359-70.

37. Yang CM, Hsu JC, Chen YR. Light-and temperature-sensitivity of chlorophyll-deficient and virescent mutants. Taiwania. 1993;38:49-56.

38. Yang CM, Hsu JC, Chen YR. Analysis of pigment-protein complexes in mungbean testa. Plant Physiol Bioch. 1995;33:135-40.

39. Huang MY, Yang MM, Jane WN, Chang YT, Yang CM. Insect-induced cecidomyiid galls deficient in light-harvesting protein complex II showing normal grana stacking. J Asia-Pacific Entomol. 2009;12:165-8.

40. Yang CM, Chang KW, Yin MH, Huang HM. Methods for the determination of chlorophylls and their derivatives. Taiwania. 1998;43:116-22.

41. Weng JH, Liao TS, Hwang MY, Chung CC, Lin CP, Chu CH. Seasonal variation in photosystem $\|$ efficiency and photochemical reflectance index of evergreen trees and perennial grasses growing at low and high elevations in subtropical Taiwan. Tree Physiol. 2006;26:1097-104.

42. Falk RH. Preparation of plant tissues for SEM. In: Scanning electron microscopy. (Chicago), IL 60666, USA: SEM Inc., AMF O"Hare; 1980.

43. Spurr AR. A low viscosity epoxy resin embedding medium for electromicroscopy. J Ultra R. 1969;26:31-43.

44. Morris DL. Quantitative determination of carbohydrates with dreywood's anthrone reagent. Sci. 1948;107:254-5.

45. Moore S, Stein WH. Photometric ninhydrin method for use in the chromatography of amino acids. J Biol Chem. 1948;176:367-88.

46. Takahashi K, Fujino K, Kikuta Y, Koda Y. Involvement of the accumulation of sucrose and the synthesis of cell-wall polysaccharides in the expansion of potato cells in response to jasmonic acid. Plant Sci. 1995;111:11-8.

47. Bradford MM. A rapid and sensitive method for thequantitation of microgram quantities of protein utilizing the principle of protein-dye binding. Anal Biochem. 1976;72:248-54.

48. Heath RL, Packer L. Photoperoxidation in isolated chloroplasts: I. Kinetics and stoichiometry of fatty acid peroxidation. Arch Biochem Biophys. 1968;125:189-98. 